\title{
Rehabilitation of pulmonary artery in congenital unilateral absence of intrapericardial pulmonary artery
}

\author{
Gi Beom Kim, MD, ${ }^{\mathrm{a}} \mathrm{Ji}$ Eun Ban, MD, ${ }^{\mathrm{b}}$ Eun Jung Bae, MD, PhD, ${ }^{\mathrm{a}}$ Chung Il Noh, MD, PhD, ${ }^{\mathrm{a}}$ \\ Woong Han Kim, MD, PhD, ${ }^{c}$ Jeong Ryul Lee, $\mathrm{MD}, \mathrm{PhD},{ }^{c}$ and Yong Jin Kim, MD, $\mathrm{PhD}^{\mathrm{c}}$
}

Objective: We evaluated the efficacy of the early rehabilitation of remnant pulmonary artery in unilateral absent intrapericardial pulmonary artery and the factors affecting pulmonary artery growth.

\begin{abstract}
Methods: We retrospectively reviewed the medical records and imaging modalities of 15 patients with unilateral absent intrapericardial pulmonary artery ( 7 left and 8 right; median age at diagnosis, 5 months) from 1991 to 2008 .

Results: The remnant pulmonary artery was found in 12 patients (mean diameter, $2.6 \pm 0.7 \mathrm{~mm}$ ) at the hilum. Eleven patients underwent operation (main pulmonary artery flap angioplasty in 5 patients; tube graft interposition in 6 patients), and 4 patients were inoperable. Transcatheter balloon angioplasty or stent implantation was required for the remaining pulmonary artery stenosis in 6 patients $(55 \%)$. The last ipsilateral lung perfusion proportion at lung perfusion scan was $39 \%$ (range, $15 \%-51 \%$ ), and the $\mathrm{Z}$ value of the last ipsilateral pulmonary artery diameter was -0.5 (range, -4.2 to 2 ). The patients with a smaller initial remnant pulmonary artery required more interventions $(P=.003)$. The final perfusion proportion of affected lung was higher in the patients treated early $(\leq 6$ months, $\mathrm{n}=7)$ than in those treated late $(>6$ months, $\mathrm{n}=4)(41.9 \% \pm 8.5 \%$ vs $24.9 \% \pm 10.7 \%$, respectively, $P=.024)$. The patients with graft interposition showed a lower perfusion proportion of affected lung than those with main pulmonary artery flap angioplasty $(P=.017)$.
\end{abstract}

Conclusions: In patients with unilateral absent intrapericardial pulmonary artery, early and aggressive management of combined surgical reconstruction and transcatheter intervention improved pulmonary artery growth and lung perfusion. (J Thorac Cardiovasc Surg 2011;141:171-8)

Unilateral absence of the intrapericardial pulmonary artery (UAPA) is a rare congenital anomaly, and one of the possible causes is proximal pulmonary arterial obstruction in conjunction with the closure of ductus arteriosus..$^{1-4}$ UAPA may occur in isolation or in association with other congenital heart diseases, such as ventricular septal defect (VSD), tetralogy of Fallot (TOF), and pulmonary atresia. ${ }^{5-7}$ If left untreated, UAPA may cause an imbalance of pulmonary ventilation/ perfusion and ipsilateral lung hypoplasia. UAPA can also induce contralateral pulmonary arterial hypertension and development of ipsilateral aortopulmonary collateral vessels. ${ }^{8-10}$ Treatments of UAPA have traditionally been somewhat conservative. ${ }^{6}$ However, patients with recurrent respiratory infection and severe hemoptysis often ultimately required a pneumonectomy. ${ }^{11}$ Since the early 1990 s, several

\footnotetext{
From the Department of Pediatrics, ${ }^{a}$ Seoul National University Children's Hospital, Seoul, South Korea; Department of Pediatrics, ${ }^{\mathrm{b}}$ Pusan National University Hospital, Busan, South Korea; and Department of Thoracic and Cardiovascular Surgery, ${ }^{c}$ Seoul National University Children's Hospital, Seoul, South Korea. Disclosures: Authors have nothing to disclose with regard to commercial support. G.B.K. and J.E.B. contributed equally.

Received for publication March 13, 2009; revisions received July 12, 2009; accepted for publication Sept 12, 2009; available ahead of print July 20, 2010.

Address for reprints: Eun Jung Bae, MD, PhD, Department of Pediatrics, Seoul

National University Children's Hospital, 101 Daehang-Ro, Jongno-gu, Seoul

110-744, South Korea (E-mail: eunjbae@plaza.snu.ac.kr).

$0022-5223 / \$ 36.00$

Copyright (C) 2011 by The American Association for Thoracic Surgery

doi:10.1016/j.jtcvs.2009.09.072
}

reports have documented successful reconstruction of absent pulmonary arteries (PAs) in infants, ${ }^{12-15}$ which is in contrast with the conservative management that was typical before this time. Early surgical intervention for UAPA was suggested to potentially preserve the affected lung vasculature and prevent morbidity and mortality in recent small series. ${ }^{16-19}$

At the Seoul National University Children's Hospital, aggressive surgical and transcatheter interventions were performed in patients with UAPA, if possible, regardless of the initial symptoms. The purpose of this study was to evaluate the efficacy of early rehabilitation of the remnant PA, factors affecting PA growth, and clinical outcomes.

\section{MATERIALS AND METHODS \\ Patient Population}

Our study focused on 15 patients presenting with UAPA at the Seoul National University Children's Hospital from June 1991 to August 2008. We excluded patients with the following conditions: (1) pulmonary atresia with major aortopulmonary collateral arteries feeding the hilar and intrapulmonary arteries; (2) 1 PA originating from the ascending aorta (hemitruncus arteriosus); (3) agenesis of 1 lung; and (4) acquired stenosis causing occlusion of a main branch of the PA. The patients were divided into 2 groups according to the time of initial surgical reconstruction of the PA: the early treatment group (group 1; $\leq 6$ months, mean age $3.1 \pm 2.2$ months, $\mathrm{n}=7$ ) and the late treatment group (group 2; $>6$ months, mean age $27.3 \pm 7.8$ months, $\mathrm{n}=4$ ). This study protocol was approved by the institutional ethics committee of the Seoul National University Children's Hospital, which waived patient consent because of the retrospective data analysis. 


$$
\begin{aligned}
& \text { Abbreviations and Acronyms } \\
& \text { LPS = lung perfusion scan } \\
& \text { NYHA }=\text { New York Heart Association } \\
& \mathrm{PA}=\text { pulmonary artery } \\
& \text { TOF }=\text { tetralogy of Fallot } \\
& \mathrm{UAPA}=\text { unilateral absence of the intrapericardial } \\
& \text { pulmonary artery } \\
& \text { VSD }=\text { ventricular septal defect }
\end{aligned}
$$

\section{Data Acquisition}

We used combinations of imaging modalities, including echocardiography, cardiac catheterization and angiography, cardiac computed tomography, cardiac magnetic resonance imaging, and lung perfusion scan (LPS), to diagnose UAPA and associated conditions. To confirm UAPA, we performed cardiac catheterization and pulmonary vein wedge angiography in 10 patients, contrast-enhanced cardiac computed tomography in 10 patients, and cardiac magnetic resonance imaging in 2 patients to identify remnant $\mathrm{PA}$ and measure the diameter at the hilum.

We also reviewed the medical records concerning associated congenital cardiac anomalies and surgical and transcatheter interventional data, such as age at the time of surgery, frequency of surgeries, surgical methods to connect UAPA, interval and method of transcatheter intervention after operation, and subsequent PA development.

The mean duration of follow-up was $6.4 \pm 4.9$ years (range, 4 months to 16.9 years). We used chest radiographs, LPS, and cardiac computed tomography for imaging in follow-up examinations. LPS was checked in all patients to assess the functional development of reconstructed PA and the condition of the affected lung. We classified the pulmonary arterial rehabilitation as follows: good, if the perfusion proportion of the affected lung was more than $40 \%$; partial, if the perfusion proportion was $20 \%$ to $40 \%$; and poor, if the perfusion proportion was less than $20 \%$.

In patients who showed remained localized pulmonary stenosis after surgery, we performed additional percutaneous transcatheter intervention, including balloon angioplasty, and measured the vessel caliber using pulmonary angiography or cardiac computed tomography to evaluate the effect of transcatheter intervention.

\section{Statistical Analysis}

Data were analyzed using the Statistical Package for the Social Sciences (version.12.0; SPSS Inc, Chicago, Ill) and presented as mean \pm standard deviation or median and range, where appropriate. Various parameters in both groups were compared using the Mann-Whitney test. Comparisons between pre-intervention and post-intervention data were made using the Wilcoxon signed-rank test. We used the Spearman rank correlation test for bivariate analysis and linear regression for multivariate analysis.

\section{RESULTS}

\section{Patient Characteristics}

Clinical characteristics of the patients are described in detail in Table 1. The median age at the time of diagnosis was 5 months (range, 1 day to 38 months). Eleven patients were male and 4 were female. Median body weight was $6 \mathrm{~kg}$ (range, 3.3-19 kg). The initial symptom was pneumonia in 7 patients, dyspnea in 2 patients, and right-sided heart failure

\begin{tabular}{|c|c|c|c|c|c|c|}
\hline No & $\begin{array}{c}\text { Absent } \\
\text { PA }\end{array}$ & $\begin{array}{l}\text { Aortic } \\
\text { arch }\end{array}$ & $\begin{array}{c}\text { Other } \\
\text { anomaly }\end{array}$ & Gender & $\begin{array}{c}\text { Age at diagnosis } \\
\text { of UAPA }\end{array}$ & $\begin{array}{c}\text { Symptoms at diagnosis } \\
\text { related to UAPA }\end{array}$ \\
\hline 1 & Left & Left & TOF & M & $10 \mathrm{~d}$ & None \\
\hline 2 & Left & Left & TOF & M & $1 \mathrm{~d}$ & None \\
\hline 3 & Left & Right & Isolated & M & $2.5 \mathrm{mo}$ & Dyspnea \\
\hline 4 & Right & Left & VSD & M & $5 \mathrm{mo}$ & Pn, HF, PHT \\
\hline 5 & Right & Left & $\mathrm{COA}$ & M & $30 \mathrm{~d}$ & Dyspnea, PHT \\
\hline 6 & Right & Left & Isolated & $\mathrm{F}$ & $5 \mathrm{mo}$ & Pn, HF, PHT \\
\hline 7 & Right & Left & Isolated & M & $2 \mathrm{mo}$ & HF, PHT \\
\hline 8 & Left & Left & TOF & M & $19 \mathrm{mo}$ & None \\
\hline 9 & Left & Left & TOF & M & $12 \mathrm{mo}$ & None \\
\hline 10 & Right & Left & Isolated & $\mathrm{F}$ & $36 \mathrm{mo}$ & Pn, PHT \\
\hline 11 & Right & Left & Isolated & $\mathrm{F}$ & $30 \mathrm{mo}$ & Pn, PHT \\
\hline 12 & Left & Right & Isolated & $\mathrm{F}$ & $38 \mathrm{mo}$ & Pn \\
\hline 13 & Left & Right & Isolated & M & $33 \mathrm{mo}$ & None \\
\hline 14 & Right & Left & Isolated & M & $4 \mathrm{mo}$ & Pn, PHT \\
\hline 15 & Right & Left & Isolated & M & $17 \mathrm{mo}$ & Pn \\
\hline
\end{tabular}
in 3 patients. Four patients with associated TOF did not show any symptoms specific to UAPA, and an incidental diagnosis of UAPA was made when TOF had been diagnosed.

Seven patients $(64 \%$ of patients without TOF) showed evidence of contralateral pulmonary arterial hypertension (defined as mean resting PA pressure $>25 \mathrm{~mm} \mathrm{Hg}$ by

TABLE 1. Clinical profiles of 15 patients with congenitally absent pulmonary artery

$P A$, Pulmonary artery; $H F$, heart failure; $P n$, pneumonia; $P H T$, pulmonary hypertension; $R P A$, right pulmonary artery; $L P A$, left pulmonary artery; $T O F$, tetralogy of Fallot; $V S D$, ventricular septal defect; $C O A$, coarctation of aorta; $L M B T$, left modified Blalock-Taussig shunt; RMBT, right modified Blalock-Taussig shunt; GT, Gore-Tex; NYHA, New York Heart Association. 
cardiac catheterization or peak tricuspid regurgitation velocity $>2.8 \mathrm{~m} / \mathrm{sec}$ by echocardiogram) at the time of UAPA diagnosis. Among them, 5 patients showed a mean PA pressure of 51.6 \pm 14.9 (range, 31-68) $\mathrm{mm} \mathrm{Hg}$ from cardiac catheterization, 1 patient (patient 7) showed $5 \mathrm{~m} / \mathrm{sec}$ of peak velocity of tricuspid regurgitation by echocardiography, and 1 patient (patient 11) showed $45 \mathrm{~mm} \mathrm{Hg}$ of right ventricle systolic pressure at operating room. Extracardiac anomalies were associated with chromosome $22 q 11$ deletion syndrome in 2 patients and achondroplasia in 1 patient. Only 1 patient with inoperable UAPA showed 1 episode of hemoptysis during follow-up in outpatient clinic. Specifically, 5 patients had symptoms of UAPA in group 1, 4 of whom had evidence of pulmonary hypertension preoperatively. Two patients in group 2 had symptoms with pneumonia and evidence of pulmonary hypertension preoperatively. On initial chest radiography, diminished ipsilateral lung volume with the shifting of heart to the ipsilateral side was observed in 7 patients $(46.6 \%)$.

\section{Anatomic Characteristics}

Isolated UAPA was diagnosed in 9 patients. Coexisting cardiac malformations included TOF (4 patients), simple VSD (1 patient), and coarctation of the aorta (1 patient). The left branch of the PA was absent in 7 patients, 4 of whom showed associated TOF and 3 of whom showed isolated UAPA. The right branch of the PA was absent in 8 patients, 1 of whom showed associated VSD, 1 of whom showed coarctation of the aorta, and 6 of whom showed iso- lated UAPA. TOF was primarily associated with left UAPA. Right UAPA was associated with a left aortic arch in all the patients, but left UAPA was associated with a right aortic arch in 2 patients and a left aortic arch in 5 patients. Two patients had an aberrant right subclavian artery (Table 1).

The remnant PA was found in 12 patients using a combination of imaging studies. The mean diameter of the remnant $\mathrm{PA}$ was $2.6 \pm 0.7 \mathrm{~mm}$ (range, $1.6-3.7 \mathrm{~mm}$; $\mathrm{Z}$ value, $<-7$ to $-2.4 ;<-7$ in 6 patients) at the hilum. However, remnant PA was not visible in 3 patients $(20 \%)$ at the hilum. Discrimination between the presence and the absence of remnant PA among image modalities was mutually complementary, although pulmonary vein wedge angiography primarily imaged the hilar remnant PA.

\section{Surgical Reconstruction of the Pulmonary Artery}

We completed surgical reconstruction of the PA in the 11 operable patients. The surgery was performed in patients with a median age of 6 months (range, 22 days to 37 months). The median body weight at the time of the first surgical reconstruction was $6.6 \mathrm{~kg}$ (range, $3.7-13.8 \mathrm{~kg}$ ). The mean elapsed time from initial diagnosis to the first surgery for PA was $2.7 \pm 3.8$ months.

Two approaches were used for surgical reconstruction of the PA. In the first approach, a posterior wall was constructed using the main PA flap (Figure 1), and the anterior wall was reconstructed by connecting it to an autologous pericardial patch (4 patients) or a polytetrafluoroethylene (Gore-Tex, WL Gore and Associates, Flagstaff, Ariz) patch (1 patient).

\begin{tabular}{|c|c|c|c|c|c|}
\hline $\begin{array}{l}\text { Size of remnant } \\
\text { PA }(\mathbf{m m})\end{array}$ & $\begin{array}{c}\text { Age at first } \\
\text { operation }\end{array}$ & $\begin{array}{c}\text { First } \\
\text { operation }\end{array}$ & $\begin{array}{l}\text { Age at second } \\
\text { operation }\end{array}$ & $\begin{array}{c}\text { Second } \\
\text { operation }\end{array}$ & NYHA \\
\hline 3 & $22 \mathrm{~d}$ & LMBT & $12 \mathrm{mo}$ & $\begin{array}{l}\text { LPA anastomosis with autologous } \\
\text { pericardial patch }\end{array}$ & I \\
\hline 3.7 & $26 \mathrm{~d}$ & RMBT, LPA anastomosis with GT patch & $7 \mathrm{mo}$ & Complete repair, RPA angioplasty & I \\
\hline 2 & $3 \mathrm{mo}$ & $\begin{array}{l}\text { LPA anastomosis with autologous } \\
\text { pericardial patch }\end{array}$ & & & I \\
\hline 2 & $6 \mathrm{mo}$ & VSD closure, 5-mm GT graft to RPA & $7 y$ & RPA angioplasty & I \\
\hline 3 & $3 \mathrm{mo}$ & $\begin{array}{l}\text { Arch repair, RPA anastomosis with } \\
\text { autologous pericardial patch }\end{array}$ & & & I \\
\hline 3.5 & $6 \mathrm{mo}$ & $\begin{array}{l}\text { RPA anastomosis with autologous } \\
\text { pericardial patch }\end{array}$ & & & I \\
\hline 3 & $2 \mathrm{mo}$ & 6-mm GT graft to RPA & & & I \\
\hline 2.3 & $22 \mathrm{mo}$ & $\begin{array}{l}\text { LMBT, LPA reconstruction with } 8-\mathrm{mm} \\
\text { pericardial tube }\end{array}$ & 39 mo & Hemashield 10 -mm tube graft & I-II \\
\hline 2.5 & $13 \mathrm{mo}$ & LMBT & $20 \mathrm{mo}$ & 8-mm GT graft to LPA & I \\
\hline 1.8 & $37 \mathrm{mo}$ & 8-mm GT graft to RPA & 5.7 Yrs & 12-mm GT graft change to RPA & I \\
\hline 2.5 & $30 \mathrm{mo}$ & 8-mm GT graft to RPA & & & I \\
\hline Invisible & - & - & & & I \\
\hline 1.6 & - & - & & & I \\
\hline Invisible & - & - & - & - & II-III \\
\hline Invisible & - & - & & & I \\
\hline
\end{tabular}



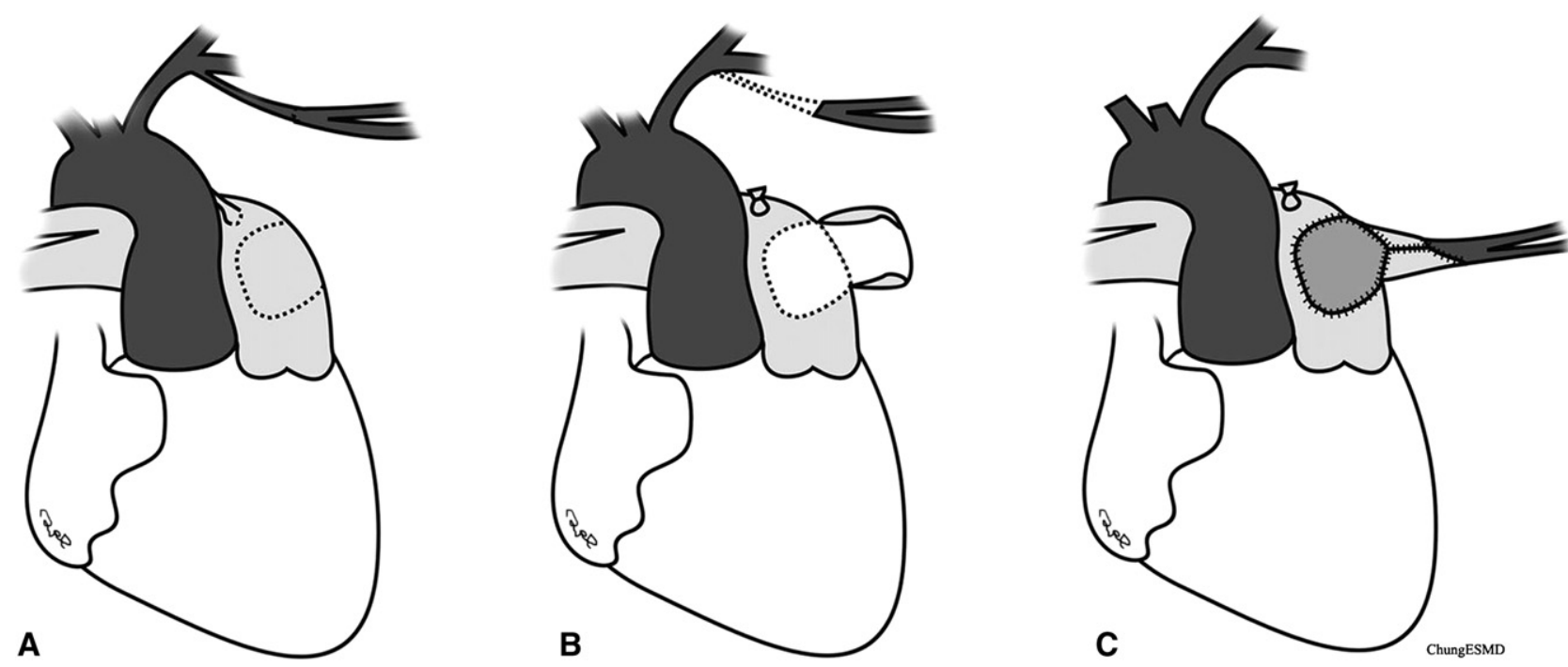

FIGURE 1. Main PA flap patch arterioplasty for unilateral absent PA. Typical feature showing absence of intrapericardial PA and small PA at the hilum (A). The posterior wall was constructed using the main PA flap (B). The anterior wall was augmented by an autologous pericardial patch or a polytetrafluoroethylene (Gore-Tex; WL Gore and Associates, Flagstaff, Ariz) patch (C).

In the second approach, we directly reconnected the interrupted PA with a polytetrafluoroethylene (Gore-Tex) tube graft in 5 patients $(5 \mathrm{~mm}$ in 1 patient, $6 \mathrm{~mm}$ in 1 patient, and $8 \mathrm{~mm}$ in 3 patients) initially at various ages. Three of the 4 patients with TOF underwent ipsilateral Blalock-Taussig shunt as the initial surgery. After the first surgical PA reconstruction, the perfusion ratio of affected lung was $25.4 \% \pm 15.7 \%$ (range, 3\%-70\%). Only 3 patients, who had undergone main PA flap angioplasty, showed good ipsilateral lung perfusion after initial surgery. The remaining 8 patients required further surgery or transcatheter intervention. Two patients (patients 8 and 10) underwent a second operation for tube graft change with larger diameter. The patients who had graft interposition to the interrupted PA showed a lower perfusion proportion at the last LPS than those who had main PA flap angioplasty $(27.7 \% \pm 10.3 \%$ vs $45.4 \% \pm 5.5 \%$, respectively; $P=.017$ ) (Figure 2).

\section{Further Rehabilitation by Transcatheter Intervention}

Despite 1 or more surgical reconstruction(s) of the PA, imaging studies of the PA and flow distribution revealed that stenosis of the PA remained in 6 patients $(55 \%)$. We performed transcatheter balloon angioplasty (13 sessions for 6 patients) and stent implantation (in 2 patients) to rehabilitate the affected PA (Table 2).

The first balloon angioplasty was performed in patients at a median interval of 26 months (range, 3-70 months) after surgical repair of the interrupted PA. The mean body weight was $13.5 \pm 3.3 \mathrm{~kg}$ at this time. Among the 6 patients, 4 underwent additional balloon angioplasty. A 10-mm Genesis stent (Cordis, Warren, NJ) was implanted in 2 patients (pa- tients 3 and 8) who showed persistent PA stenosis after several balloon angioplasties.

The narrowest diameter of the focal stenosis increased from $2.4 \pm 1.4 \mathrm{~mm}(\mathrm{Z}$ value, $<-6)$ before balloon angioplasty to $6.6 \pm 1.2 \mathrm{~mm}$ ( $\mathrm{Z}$ value, -4.2 to -1.5$)$ immediately after the last transcatheter intervention $(P=.027)$. The perfusion proportion of the affected lung increased from $15.0 \% \pm 10.0 \%$ to $31.4 \% \pm 13.2 \% \quad(P=.028)$ (Figure 3). The main pulmonary arterial systolic pressure slightly decreased from $58.7 \pm 13.9 \mathrm{~mm} \mathrm{Hg}$ before transcatheter intervention to $51.2 \pm 17.1 \mathrm{~mm} \mathrm{Hg}$ immediately after the last intervention $(P=.027)$. The patients who had smaller initial remnant PA showed lower perfusion proportions of the affected lung at the first postsurgical LPS $(P=.017, \gamma=0.729)$, and they required more interventions for PA rehabilitation $(P=.003, \gamma=-0.797)$.

\section{Outcomes and Prognostic Factors}

No patient died during follow-up. On follow-up, all 7 patients in group 1 (early treatment) were asymptomatic and in New York Heart Association (NYHA) class I. Group 2 (late treatment) included 3 patients in NYHA class I and 1 patient in NYHA class I to II. Severe pulmonary arterial hypoplasia and stenosis remained in 2 patients of group 2 (patients 8 and 9) despite both surgical and transcatheter interventions (Table 2).

The median value of last ipsilateral lung perfusion proportion was $39 \%$ (range, 15-51), and the $Z$ value of ipsilateral PA was -0.4 (range, -4.2 to 2 ). The last perfusion proportion of affected lung was higher in group 1 than in group 2 $(41.9 \% \pm 8.5 \%$ vs $24.9 \% \pm 10.7 \%$, respectively, $P=.024)$, although the $\mathrm{Z}$ values of the last ipsilateral PA 


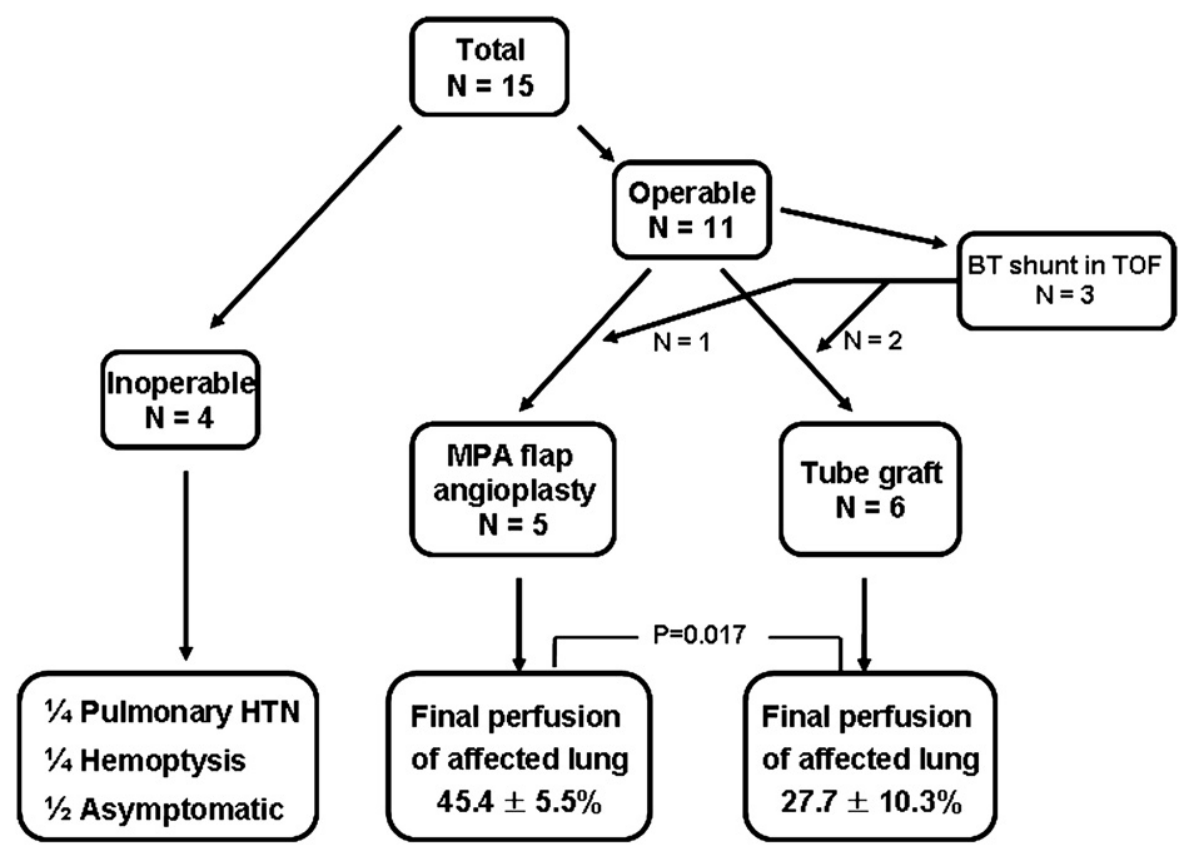

FU: $5.2 \pm 5.0$ years

FU: $6.8 \pm 5.0$ years

FIGURE 2. Overall clinical course of 15 patients with unilateral absent PA. The diagram shows PA reconstruction methods and the final pulmonary blood flow in 11 operable patients. The patients who had graft interposition to the interrupted PA had lower perfusion proportions of the affected lung as determined at the last LPS than the patients who had main PA flap angioplasty. BT, Blalock-Taussig; TOF, tetralogy of Fallot; $M P A$, main pulmonary artery; $H T N$, hypertension.

size were similar $(-0.16 \pm 1.66$ in group $1,-1.6 \pm 1.78$ in group 2, respectively, $P=.412$ ). Fewer transcatheter interventions were required in group 1 than in group $2(1.0 \pm$ 1.5 vs. $2.0 \pm 2.2$, respectively) (Table 3 ). In both groups, pulmonary arterial rehabilitation of UAPA was good in 5 of 11 patients, partial in 4 of 11 patients, and poor in 2 of 11 patients. Multivariate analysis showed no significant risk factors for poor PA rehabilitation.
Four patients could not undergo surgery because the remnant PA could not be visualized $(\mathrm{n}=3)$ or the remnant PA diameter at the hilum was too small $(1.6 \mathrm{~mm}, \mathrm{n}=1)$. One of these patients (number 14) was diagnosed at 4 months of age in 1995 and followed up until now. This patient is in NYHA class II to III and is taking supportive medication for severe pulmonary arterial hypertension. The other 3 patients are of preschool age and were asymptomatic at the last follow-up,

TABLE 2. Result of combined surgical and transcatheter interventions for pulmonary artery rehabilitation

\begin{tabular}{|c|c|c|c|c|c|c|c|c|c|}
\hline No & $\begin{array}{c}\text { Absent } \\
\text { PA } \\
\end{array}$ & $\begin{array}{c}\text { Early postoperative } \\
\text { perfusion }(\%) \\
\text { (ipsilateral/contralateral) }\end{array}$ & $\begin{array}{l}\mathbf{N} \\
\text { (I) }\end{array}$ & $\begin{array}{c}\text { Type } \\
\text { (I) }\end{array}$ & $\begin{array}{c}\text { Age at } \\
\text { initial I }\end{array}$ & $\begin{array}{c}F / U \\
\text { duration }(y)\end{array}$ & $\begin{array}{c}\text { Last LPS (\%) } \\
\text { (ipsilateral/ } \\
\text { contralateral) }\end{array}$ & $\begin{array}{c}\text { Age at last } \\
\text { LPS (y) }\end{array}$ & $\begin{array}{c}\text { Last diameter of PA } \\
(\mathrm{Z} \text { value })(\mathbf{m m}) \\
\text { (ipsilateral/contralateral) }\end{array}$ \\
\hline \multicolumn{10}{|c|}{ Early treatment group } \\
\hline 1 & Left & $33 / 66$ & 1 & BAP*1 & $44 \mathrm{mo}$ & 8 & $48 / 52$ & 4.8 & $13(1.6) / 22.3(>2)$ \\
\hline 2 & Left & $54 / 46^{*}$ & 0 & & & 5.1 & $40 / 60$ & 5 & $8(-1.5) / 11(1.2)$ \\
\hline 3 & Left & $10 / 90$ & 4 & BAP*3, Stent $* 1$ & $6 \mathrm{mo}$ & 4.8 & $39 / 61$ & 5 & $10(0.8) / 13(>2)$ \\
\hline 4 & Right & $16 / 84$ & 2 & $\mathrm{BAP} * 2$ & $76 \mathrm{mo}$ & 12.7 & $40 / 60$ & 12 & $10(-2) / 13(0)$ \\
\hline 5 & Right & $46 / 54$ & 0 & & & 11.7 & $49 / 51$ & 6.5 & $8.2(-1.8) / 14(>2)$ \\
\hline 6 & Right & $70 / 30 * *$ & 0 & & & 5.3 & $51 / 49$ & 2.5 & $10.5(2) / 14(>2)$ \\
\hline 7 & Right & $26 / 74$ & 0 & Coil, collateral A & & 0.4 & & & $6.6(-0.2) / 11.9(>2)$ \\
\hline \multicolumn{10}{|c|}{ Late treatment group } \\
\hline 8 & Left & $16 / 84$ & 5 & BAP*4 Stent* 1 & $56 \mathrm{mo}$ & 16.9 & $18 / 28$ & 16 & $6.8(-4.2) / 14.5(1.5)$ \\
\hline 9 & Left & $3 / 97$ & 1 & $\mathrm{BAP}^{*} 1$ & $34 \mathrm{mo}$ & 5.1 & $15 / 85$ & 2.8 & $7.6(-0.4) / 14(>2)$ \\
\hline 10 & Right & $12 / 88$ & 2 & $\mathrm{BAP} * 2$ & $45 \mathrm{mo}$ & 3.2 & $28 / 72$ & 6 & $7.8(-1.3) / 13(>2)$ \\
\hline 11 & Right & $33 / 67$ & 0 & & & 2.3 & $39 / 61$ & 4.3 & $9.5(-0.5) / 11.5(1)$ \\
\hline
\end{tabular}

$P A$, Pulmonary artery; $B A P$, balloon angioplasty; $I$, transcatheter intervention; $L P S$, lung perfusion scan; $A$, artery. A period of ipsilateral over-perfusion existed because of contralateral PA stenosis $(*)$ or contralateral PA hypertension $(* *)$. 

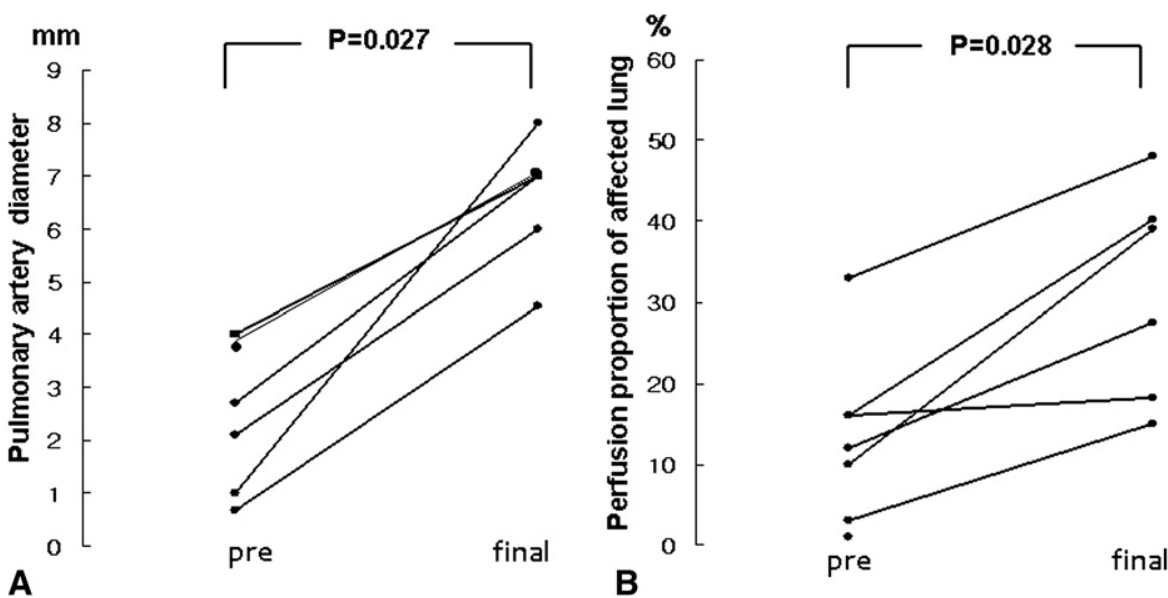

FIGURE 3. The effect of percutaneous transcatheter intervention for residual ipsilateral pulmonary stenosis. The mean narrowest diameter of the stenotic PA increased from $2.4 \pm 1.4 \mathrm{~mm}$ before balloon angioplasty to $6.6 \pm 1.2 \mathrm{~mm}$ after the final intervention (A), and mean perfusion proportion of the affected lung increased from $15.0 \% \pm 10.0 \%$ to $31.4 \% \pm 13.2 \%$ after the final intervention (B).

although 1 patient showed 1 episode of mild hemoptysis during outpatient clinic follow-up.

\section{DISCUSSION}

UAPA is a rare congenital anomaly first described by Fraentzel in $1868 .^{1}$ The major embryologic cause for UAPA is involution of the proximal sixth aortic arch (destined to become the PA), which leads to the absence of the

TABLE 3. Clinical data of early (group 1) and late (group 2) treatment group

\begin{tabular}{|c|c|c|c|}
\hline & Group 1 & Group 2 & $P$ value \\
\hline $\mathrm{N}$ & 7 & 4 & NA \\
\hline Absent PA (right/left) & $4 / 3$ & $2 / 2$ & .652 \\
\hline Associated TOF, N (\%) & $2(28.6 \%)$ & $2(50 \%)$ & .470 \\
\hline $\begin{array}{l}\text { Age at initial operation } \\
\text { (mo) }\end{array}$ & $3.1 \pm 2.2$ & $27.3 \pm 7.8$ & .006 \\
\hline $\begin{array}{l}\text { Initial PA diameter }(\mathrm{mm}) \\
\quad(\mathrm{Z} \text { valve })\end{array}$ & $\begin{aligned} 2.89 & \pm 0.66 \\
(-4.66 & \pm 1.79)\end{aligned}$ & $\begin{array}{l}2.28 \pm 0.33 \\
\quad(<-7)\end{array}$ & .164 \\
\hline $\begin{array}{l}\text { Age at initial PA } \\
\text { intervention (mo) }\end{array}$ & $42.0 \pm 35.0$ & $45.0 \pm 11.0$ & 1.0 \\
\hline $\begin{array}{l}\text { Body weight at initial PA } \\
\text { intervention }(\mathrm{kg})\end{array}$ & $13.7 \pm 5.1$ & $13.3 \pm 0.6$ & .7 \\
\hline $\begin{array}{l}\text { Mode of surgery } \\
\text { (patch/tube graft) }\end{array}$ & $5 / 2$ & $0 / 4$ & .045 \\
\hline $\begin{array}{l}\text { No. of affected PA } \\
\text { operations }\end{array}$ & $1.14 \pm 0.38$ & $1.50 \pm 0.58$ & .412 \\
\hline $\begin{array}{l}\text { No. of affected PA } \\
\text { interventions }\end{array}$ & $1.0 \pm 1.5$ & $2.0 \pm 2.2$ & .412 \\
\hline $\begin{array}{l}\text { Ipsilateral LPS ratio, } \\
\text { pre-intervention }\end{array}$ & $31.3 \pm 16.7$ & $16.0 \pm 12.6$ & .257 \\
\hline $\begin{array}{l}\text { Ipsilateral LPS ratio, final } \\
\text { intervention }\end{array}$ & $41.9 \pm 8.5$ & $24.9 \pm 10.7$ & .024 \\
\hline $\begin{array}{l}\text { Ipsilateral PA diameter Z } \\
\text { value, last }\end{array}$ & $-0.16 \pm 1.66$ & $-1.6 \pm 1.78$ & .412 \\
\hline
\end{tabular}

intrapericardial PA and the persistence of distal sixth aortic arch (destined to become the ductus arteriosus) to the hilar PA. ${ }^{20}$ Since the first report, the natural course of the anomaly has been documented in numerous case reports. ${ }^{5,6,10}$ This study contributes significantly to our understanding of UAPA, because we could compare effect of surgical methods and the timing of treatment on the rehabilitation of PA in congenital UAPA with the relatively large number of cases (15 patients) at a single center.

Because early diagnosis and surgical intervention for UAPA may preserve the affected lung vasculature and prevent various complications and mortality, ${ }^{17}$ we performed surgical treatment as early as possible. Since 1991, we have performed surgical reconstruction in 11 patients (73.3\% of patients in this study) who had accessible remnant PA at the hilum, according to our policy of aggressive surgical reconstruction of UAPA regardless of the initial symptom. No patients died after surgical reconstruction, and most patients were in NYHA class I.

The optimal age for surgical construction of UAPA is difficult to determine. Since the late 1990s, several reports have suggested aggressive, early surgery for absent PAs. Imanaka et $\mathrm{al}^{21}$ reported that surgical correction should be undertaken as early as possible. They reported a case of a 2-month-old boy with left UAPA associated with VSD. They observed the infant for 6 months and performed corrective surgery when he was 8 months old because the symptoms were mild. However, they could not complete the PA reconstruction because they could not find remnant PA at the hilum in the operative field. When they performed a pneumonectomy 3 months later because of massive hemoptysis in the boy, they did not find remnant left PA that had previously existed, even by histologic examination. Murphy et al ${ }^{16}$ reported on 7 patients with a disconnected PA and concluded that earlystage reconstruction improved pulmonary perfusion to 
a nearly normal ratio. We confirmed the favorable effect of early surgical reconstruction of absent PA in the 11 patients who underwent surgery in our study.

The early treatment group (group 1, surgery performed in infants aged $<6$ months) had a higher final perfusion proportion of the affected lung and required fewer catheterizations than the late treatment group (group 2, surgery performed in infants aged $>6$ months) (Table 3 ). An animal model of pigs with a ligation of the left PA at birth showed that the PAs at the hilum shrank and were often obliterated within 4 to 6 months. ${ }^{22}$ Therefore, early detection of the UAPA is crucial, and aggressive surgical correction should be performed as early as possible for effective reconstruction of absent PA.

Significant localized stenosis of the affected PA remained in 6 of our patients $(55 \%)$ despite successful PA reconstruction. These patients underwent serial transcatheter balloon angioplasty to rehabilitate the affected PA, and 2 of them required stent implantation. Pulmonary arterial development after transcatheter intervention was satisfactory in most patients (Table 2, Figure 3), and no acute or late complications were observed after aggressive transcatheter interventions. The long-term outcomes of patients with reconstructed PAs, including the effectiveness of transcatheter interventions, are still unknown because of limited reports addressing this issue.

Outcomes differed according to the approach to PA reconstruction, either main PA flap or tube graft. We found that the patients who had graft interposition to the interrupted PA showed lower perfusion proportions of the affected lung at the final LPS.

The patients in the early treatment group underwent main PA flap angioplasty more frequently than those in the late treatment group $(P=.045)$. The relatively bigger remnant PA at the hilum and shorter distance from the main PA to the hilum in the young infant may enable surgeons to choose main PA flap angioplasty instead of graft interposition. Because tube graft does not grow naturally, the graft needs to be changed for a bigger size up to adult size $(>12 \mathrm{~mm})$ as the patient grows ${ }^{23}$ and may make remained pulmonary stenosis of the affected PA less effectively ballooned. Reconstruction of absent PA using the main PA flap may have favorable long-term outcomes, including improved pulmonary blood flow, although the small number of patients in this study limits any definitive decision as to which surgical approach is appropriate. In addition, the mean follow-up duration of the patients undergoing surgery was relatively short ( $6.8 \pm 5.0$ years); therefore, more longterm, longitudinal, observational studies are required to confirm the appropriate type of surgery for long-term rehabilitation of UAPA.

We do not have long-term results for patients who were unable to undergo surgery in this study because of relatively short follow-up periods (5.2 \pm 5.0 years). By using the largest literature review of patients with UAPA, we estimate an overall mortality of $7 \% .^{10}$ The outlook may be unfavorable for our inoperable patients, especially for the patient with pulmonary hypertension, and heart-lung transplantation may be necessary as an alternative treatment option.

Conclusions based on these results are limited because each treatment group and surgical method had a small number of patients. This small number probably reduced the likelihood of statistical differences between some parameters, but we believe that many of the conclusions are still valid.

\section{CONCLUSIONS}

Because untreated UAPA can result in hemoptysis, pulmonary hypertension, right ventricular failure, and even death, early detection and aggressive surgical reconstruction of the remnant PA are crucial for effective treatment of an absent PA. Age at initial treatment, initial remnant PA size, and types of surgery influenced the outcome.

The authors thank Dr Eui-Suk Chung, at the Department of Thoracic and Cardiovascular Surgery, Seoul National University Bundang Hospital, for the informative illustration about main PA flap arterioplasty in UAPA.

\section{References}

1. Fraentzel O. Ein Fall von abnormer communication der Aorta mit der Arterior pulmonalis. Virchow's Arch Path Anat. 1868;43:420.

2. Pfefferkorn JR, Loser H, Pech G, Toussaint R, Hilgenberg F. Absent pulmonary artery. A hint to its embryogenesis. Pediatr Cardiol. 1982;3:283-6.

3. Freedom RM, Moes CA, Pelech A, Smallhorn J, Rabinovitch M, Olley PM, et al. Bilateral ductus arteriosus (or remnant): an analysis of 27 patients. Am J Cardiol. 1984;53:884-91

4. Sotomora RF, Edwards JE. Anatomic identification of so-called absent pulmonary artery. Circulation. 1978;57:624-33.

5. Pool PE, Vogel JH, Blount SG Jr. Congenital unilateral absence of a pulmonary artery. The importance of flow in pulmonary hypertension. Am J Cardiol. 1962; 10:706-32.

6. Shakibi JG, Rastan H, Nazarian I, Paydar M, Aryanpour I, Siassi B. Isolated unilateral absence of the pulmonary artery. Review of the world literature and guidelines for surgical repair. Jpn Heart J. 1978;19:439-51.

7. Bockeria LA, Podzolkov VP, Makhachev OA, Zelenikin MA, Alekian BG, Ilyin VN, et al. Surgical correction of tetralogy of Fallot with unilateral absence of pulmonary artery. Ann Thorac Surg. 2007;83:613-8.

8. Sakai S, Murayama S, Soeda H, Furuya A, Ono M, Ro T, et al. Unilateral proximal interruption of the pulmonary artery in adults: CT findings in eight patients. J Comput Assist Tomogr. 2002;26:777-83.

9. Presbitero P, Bull C, Haworth SG, de Leval MR. Absent or occult pulmonary artery. Br Heart J. 1984;52:178-85.

10. Ten Harkel AD, Blom NA, Ottenkamp J. Isolated unilateral absence of a pulmonary artery: a case report and review of the literature. Chest. 2002;122: 1471-7.

11. Griffin N, Mansfield L, Redmond KC, Dusmet M, Goldstraw P, Mittal TK et al. Imaging features of isolated unilateral pulmonary artery agenesis presenting in adulthood: a review of four cases. Clin Radiol. 2007;62: 238-44.

12. Moreno-Cabral RJ, McNamara JJ, Reddy VJ, Caldwell P. Unilateral absent pulmonary artery: surgical repair with a new technique. J Thorac Cardiovasc Surg 1991;102:463-5.

13. Sreeram N, Asante-Korang A, Ladusans E. Distal ductal origin of the right pulmonary artery: prospective diagnosis and primary repair in infancy. Int J Cardiol. 1992;35:272-4.

14. Milanesi O, Stellin G, Zucchetta P. Isolation of the left pulmonary artery and ventricular septal defect? Successful staged management. Cardiol Young. 1995;5 180-3. 
15. Salaymeh KJ, Kimball TR, Manning PB. Anomalous pulmonary artery from the aorta via a patent ductus arteriosus: repair in a premature infant. Ann Thorac Surg. 2000;69:1259-61.

16. Murphy DN, Winlaw DS, Cooper SG, Nunn GR. Successful early surgical recruitment of the congenitally disconnected pulmonary artery. Ann Thorac Surg. 2004;77:29-35.

17. Welch K, Hanley F, Johnston T, Cailes C, Shah MJ. Isolated unilateral absence of right proximal pulmonary artery: surgical repair and follow-up. Ann Thorac Surg. 2005;79:1399-402.

18. Hamdan MA, Al Meshham Y, Najm HK. Successful one-stage repair of unilateral agenesis of pulmonary artery. Pediatr Cardiol. 2005;26:724-6.

19. Peirone A, Lee KJ, Yoo SJ, Musewe N, Smallhorn J, Benson L. Staged rehabilitation of ductal origin of the left pulmonary artery in an infant Fallot's tetralogy. Catheter Cardiovasc Interv. 2003;59:392-5.
20. Apostolopoulou SC, Kelekis NL, Brountzos EN, Rammos S, Kelekis DA. "Absent" pulmonary artery in one adult and five pediatric patients: imaging, embryology, and therapeutic implications. AJR Am J Roentgenol. 2002;179: 1253-60.

21. Imanaka K, Shimizu S, Matsumoto J, Hashizume K, Tsuchiya K, Takemura T. Unilateral absence of pulmonary artery and ventricular septal defect in an infant. Ann Thorac Surg. 1998;66:251-2.

22. Haworth SG, McKenzie SA, Fitzpatrick ML. Alveolar development after ligation of left pulmonary artery in newborn pig: clinical relevance to unilateral pulmonary artery. Thorax. 1981;36:938-43.

23. Snider AR, Enderlein MA, Teitel DF, Juster RP. Two-dimensional echocardiographic determination of aortic and pulmonary artery sizes from infancy to adulthood in normal subjects. Am J Cardiol. 1984;53:218-24. 